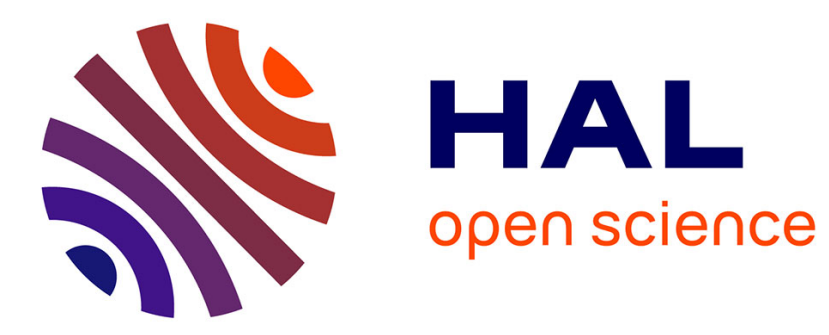

\title{
Numerical modelling of nearshore wave energy resource in the Sea of Iroise \\ Nicolas Guillou, Georges Chapalain
}

\section{To cite this version:}

Nicolas Guillou, Georges Chapalain. Numerical modelling of nearshore wave energy resource in the Sea of Iroise. Renewable Energy, 2015, 83, pp.942 - 953. 10.1016/j.renene.2015.05.021 . hal01672292

\section{HAL Id: hal-01672292 \\ https://hal.science/hal-01672292}

Submitted on 29 Jan 2018

HAL is a multi-disciplinary open access archive for the deposit and dissemination of scientific research documents, whether they are published or not. The documents may come from teaching and research institutions in France or abroad, or from public or private research centers.
L'archive ouverte pluridisciplinaire HAL, est destinée au dépôt et à la diffusion de documents scientifiques de niveau recherche, publiés ou non, émanant des établissements d'enseignement et de recherche français ou étrangers, des laboratoires publics ou privés. 


\title{
Numerical modelling of nearshore wave energy ressource in the Sea of Iroise
}

\author{
by \\ Nicolas Guillou and Georges Chapalain \\ Renewable Energy \\ 2015, Volume 83, pp. 942-953 \\ http://dx.doi.org/10.1016/j.renene.2015.05.021
}

Please note that this is an author-produced PDF of the draft of the manuscript submitted to Renewable Energy. The definitive publisher-authenticated version is available on the publisher Web site. 


\title{
Numerical modelling of nearshore wave energy resource in the Sea of Iroise.
}

\author{
Nicolas Guillou ${ }^{\mathrm{a}, *}$, Georges Chapalain ${ }^{\mathrm{a}}$ \\ ${ }^{a}$ Laboratoire de Génie Côtier et Environnement (LGCE), Cerema/DTecEMF/DS, 155 \\ rue Pierre Bouguer Technopôle Brest-Iroise - BP 5 - 29280 Plouzané, France
}

\begin{abstract}
An unstructured version of SWAN (Simulating WAves Nearshore) is implemented in the Sea of Iroise (western Europe) to assess the wave energy resource at high spatial resolutions in coastal areas. Numerical results are compared with available measurements of the significant wave height and the peak period at nine locations including (1) long-term offshore observations and (2) medium to short-term data acquired during field campaigns. A medium-term evaluation of the wave energy resource for a eight-years period (2004-2011) is performed exhibiting major nearshore energetic patterns off the isles of Ushant and Sein and in the coastal areas of the bay of Audierne, the Crozon Peninsula and the northern coastline. The variability of wave power production is estimated revealing in accordance with numerical modelling conducted over the European shelf seas significant inter-seasonal and inter-annual evolutions of the resource in the Sea of Iroise. These changes appear particularly noticeable during the winter period with opposite situations
\end{abstract}

\footnotetext{
*Corresponding author

Email addresses: nicolas.guillou@cerema.fr (Nicolas Guillou ), georges.chapalain@cerema.fr (Georges Chapalain)
} 
in the distribution of monthly average wave energy flux. In the perspective of the implementation of wave energy converters devices, the present assessment is finally exploited to investigate the local distributions of wave energy flux against periods and directions in areas of maximum mean wave power. Keywords: marine renewable energy, SWAN, unstructured grid, Brittany, western Europe.

\section{Introduction}

The exploitation of marine renewable energy (MRE) is recognised by many countries as a promising alternative to restricted fossil fuel resources both achieving future energy security and mitigating the effects of climate change induced by human activities [1]. Among the different MREs, wave energy constitutes an abundant resource of high power density in the nearshore areas [2]. Wave energy converters (WEC) devices may thus theoretically be implemented in many more potential sites than tidal energy systems whose locations are generally restricted to a small number of strong-currents coastal areas like estuaries or shallow-water straits [3, 4].

Varying on similar timescales to that of the weather climate, wave energy presents however strong seasonal and inter-annual variations $[5,6,7]$ which need to be precisely characterised to optimise WEC location and design. Third-generation spectral wave models are traditionally implemented in combination with in-situ and/or remote measurements to (1) encompass the processes of generation, dissipation and nonlinear wave-wave interactions from offshore opened ocean to coastal regions [8], (2) approach the associated wave-energy variability and (3) extrapolate the resource at extended 
time scales and locations [9].

The north-western European shelf environment (Fig. 1-a) presents one of the most significant wave energy resource in the world [10] with estimated offshore mean wave power of $60 \mathrm{~kW} \mathrm{~m}^{-1}$ [11] exceeding $40 \mathrm{~kW} \mathrm{~m}^{-1}$ in numerous localised areas [12]. Whereas large-scale models have been implemented to assess this resource $[6,11,13]$, the resulting offshore estimations were generally not sufficiently accurate for selecting the optimum site for a coastal wave energy operation. Numerous nearshore numerical studies have thus been conducted to refine this assessment in wave-exposed regions along the west coast of Ireland [14], the Southwest of UK [15], the Portuguese coastline [16], in some parts of the Spanish coast $[3,17]$ or more recently in the western continental French coast $[18,19]$. A detailed review of these modelling has recently been established by Guedes Soares et al. [20].

Excepts seldom investigations [7, 13], most of these works rely on structured regular or curvilinear computational meshes introducing constraints in the wave-energy simulation: (1) a reduced spatial resolution at the coast, (2) numerics and physics mismatches problems of additional boundaries in the case of embedded domains and/or (3) reduced CPU performance associated with an increased number of grid nodes [21]. The unstructured grid offers an interesting alternative to these problems reaching accurate local grid refinement and capturing simultaneously spatial scales from tens of kilometres offshore to tens of meters nearshore.

The present study extends the coastal numerical evaluations of the wave energy resource relying on an unstructured grid computation. The site of application is the Sea of Iroise located in the western extend of Brittany 

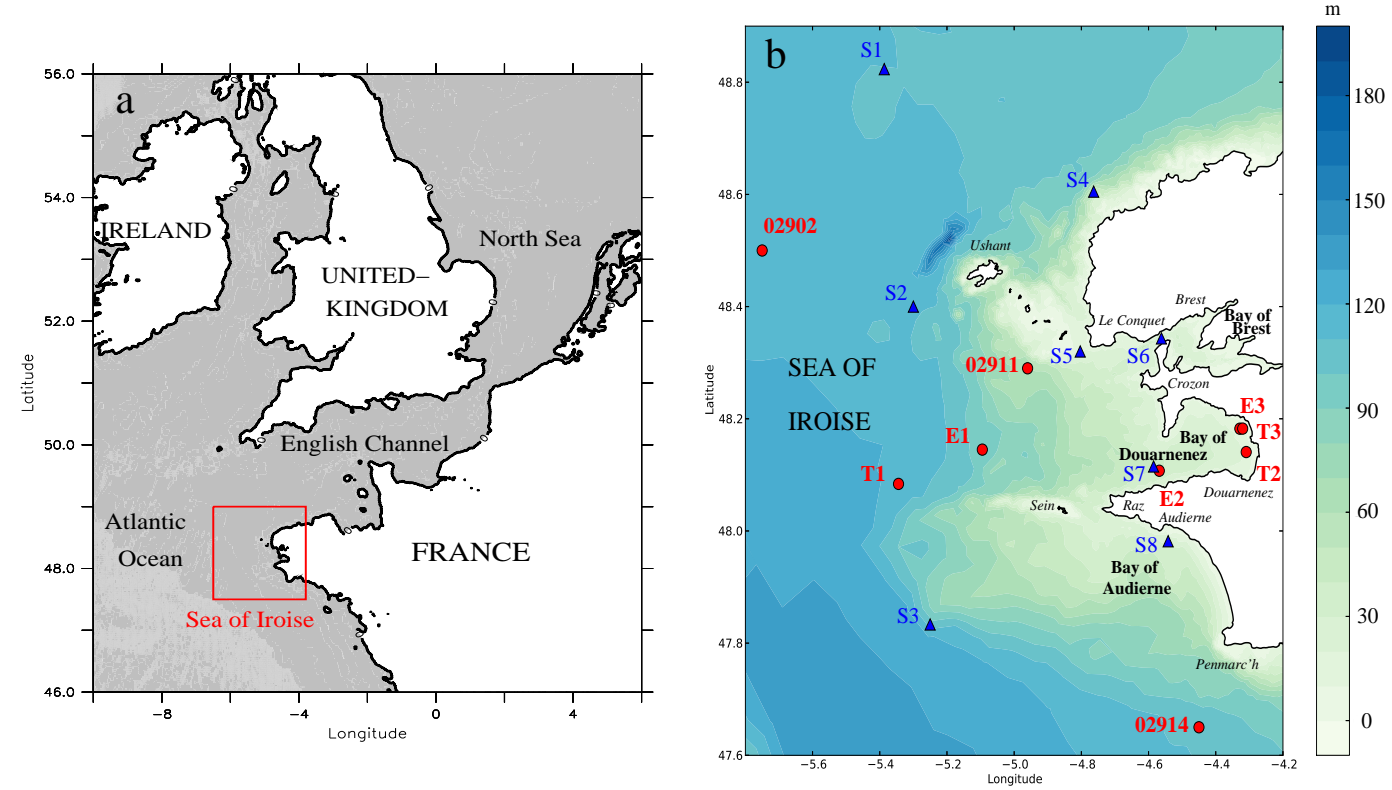

Figure 1: (a) Location of the Sea of Iroise in the north-western European continental shelf. (b) Bathymetry of the Sea of Iroise with the locations of the available measurements points (red circles for wave buoys and blue triangles for currents measurements).

(Fig. 1-b). In spite of noticeable wave power decrease over the European continental shelf predominantly associated with bottom friction, this environment is the most energetic region along the French coasts with significant wave height reaching values over $10 \mathrm{~m}$ offshore (Fig. 2) and associated mean wave power estimated around $50 \mathrm{~kW} \mathrm{~m}^{-1}$ by Mattarolo et al. [11]. The use of an unstructured mesh appears here particularly suited to (1) capture, offshore, the limits of the isles of Ushant and Sein and (2) approach, nearshore, the variations of the bathymetry and the evolution of the irregular coastline characterised by a series of bays (e.g., bays of Brest and Douarnenez) and prominent headlands (e.g., Raz, Penmarc'h).

The modelling approach is based on the phase-averaged wave model 


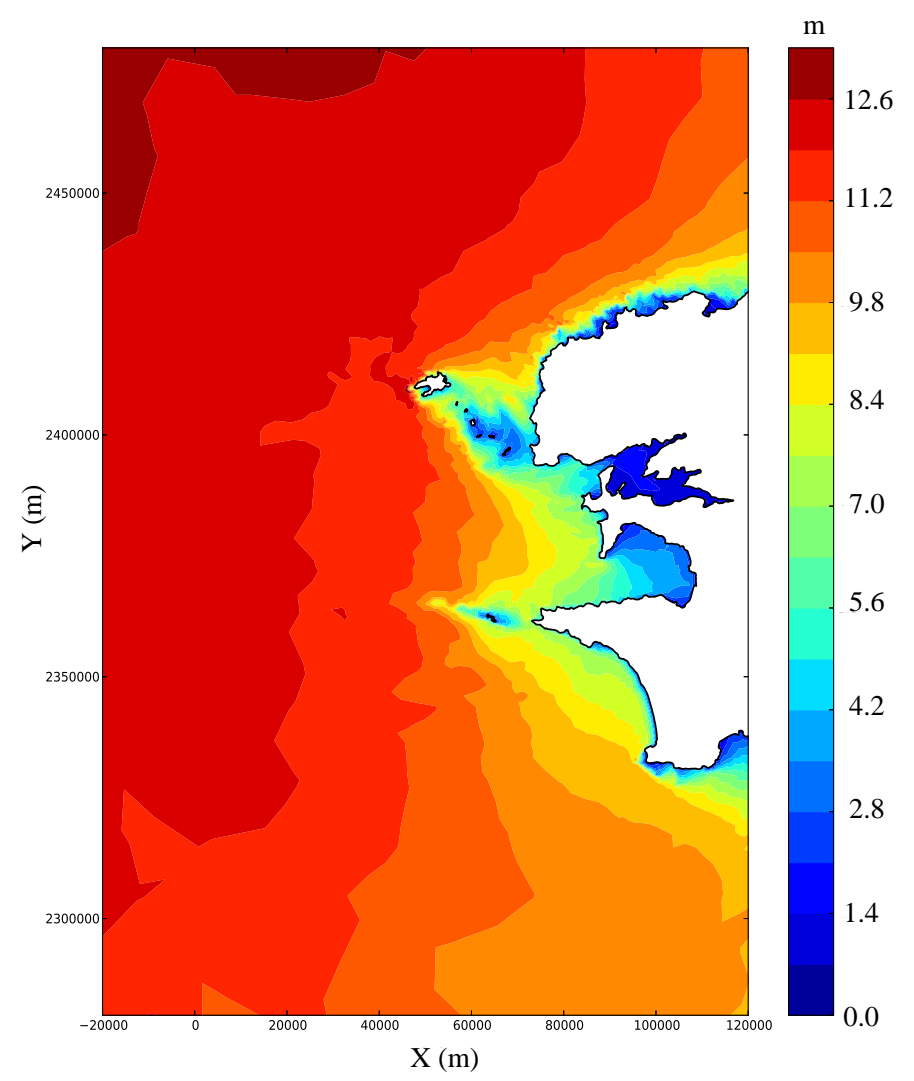

Figure 2: Predicted maximum significant wave height over the period 2004-2011 in the Sea of Iroise.

SWAN (Simulating WAves Nearshore) (version 40.91) [22] modified to integrate an enhanced additional dissipation term for current-induced whitecapping [23] (section 2). Models predictions are evaluated against available observations of the significant wave height and the peak period at nine locations evenly distributed over the computational domain (section 3). A medium-term evaluation of the wave energy resource is performed for a eightyears period (1) exhibiting the major nearshore energetic patterns (section 4.1) and (2) investigating the inter-annual and seasonal variabilities of wave 
power at the scale of the Sea of Iroise (sections 4.2 and 4.3). In the perspective of WEC implementation, four locations of maximum mean wave power are finally selected (section 5.1) and analysed focusing on the distributions of the wave energy flux against periods and directions (section 5.2).

\section{Model description}

\subsection{Theoretical formulations}

SWAN computes the evolution of the wave action density $N(=E / \sigma$ with $E$ the wave energy density distributed over intrinsic frequencies $\sigma$ and propagation directions $\theta$ ) using the time-dependent spectral action balance equation:

$$
\frac{\partial N}{\partial t}+\vec{\nabla}_{x, y} \cdot\left[\left(\vec{c}_{g}+\vec{U}\right) N\right]+\frac{\partial}{\partial \sigma}\left(c_{\sigma} N\right)+\frac{\partial}{\partial \theta}\left(c_{\theta} N\right)=\frac{S_{t o t}}{\sigma}
$$

where $t$ denotes times, $x$ and $y$ are the geographical coordinates and $\nabla_{x, y}$ is the horizontal gradient operator. $\vec{c}_{g}$ is the intrinsic group velocity vector while quantities $c_{\sigma}$ and $c_{\theta}$ are the propagation velocities in spectral space $(\sigma, \theta) . \vec{U}$ is finally the ambient depth-averaged current. The right-hand side of eq. 1, $S_{t o t}$, contains the source and sink terms of physical processes which generate, dissipate or redistribute wave energy:

$$
S_{t o t}=S_{n l 4}+S_{n l 3}+S_{i n}+S_{w c}+S_{b o t}+S_{b r k}+S_{w c, c u r}
$$

The parameterisation adopted for each terms is briefly detailed hereafter. The redistribution of energy by nonlinear quadruplet wave-wave interactions $S_{n l 4}$ is computed with the Discrete Interaction Approximation of Hasselmann et al. [24]. The non-linear triad redistribution of wave energy $S_{n l 3}$ is approached with the Lumped Triad Approximation derived by Eldeberky 
[25]. The transfer of energy from the wind to the waves $S_{i n}$ and the dissipation of wave energy due to whitecapping $S_{w c}$ are approached with the saturation-based model of van der Whesthuysen [26] combined with the wind input formulation proposed by Yan [27]. The sink term of energy dissipation by bottom friction $S_{b o t}$ is computed according to the formulation proposed by Madsen et al. [28]. Energy dissipation in random waves due to depthinduced breaking $S_{b r k}$ is quantified according to Battjes and Janssen [29]. An additional dissipation term $S_{w c, c u r}$ recently proposed by van der Westhuysen [23] is finally included to limit the overprediction of wave height on negative current gradients (accelerating opposing currents or decelerating following currents). Its implementation is conducted following previous recent calibrations of this dissipation term in SWAN [23, 30].

The wave energy flux (also denominated the wave power) is computed on its $x-$ and $y-$ components with the two following expressions:

$$
P_{x}=\rho g \int_{0}^{2 \pi} \int_{0}^{\infty} E(\sigma, \theta) c_{x}(\sigma, \theta) \cos \theta d \sigma d \theta
$$

and

$$
P_{y}=\rho g \int_{0}^{2 \pi} \int_{0}^{\infty} E(\sigma, \theta) c_{y}(\sigma, \theta) \sin \theta d \sigma d \theta
$$

where $c_{x}$ and $c_{y}$ are the propagation velocities of wave energy in spatial space, $\rho$ is the water density and $g$ is the acceleration of gravity. The wave power magnitude is finally given by the following approximation

$$
P=\left(P_{x}^{2}+P_{y}^{2}\right)^{1 / 2}
$$

It is expressed in $\mathrm{W} \mathrm{m}^{-1}$ characterising the wave energy flux per unit length of wave front. 
The wave action balance equation is expressed on a cartesian coordinate system and solved on an unstructured grid, a constant directional resolution and an exponential frequency distribution. Further details about the mathematical expressions of sources and sinks are available in SWAN technical documentation [31] and associated scientific literature [21].

\subsection{Setup}

SWAN is set up on an unstructured computational grid covering the Sea of Iroise and comprising 9971 nodes and 18443 elements with a size of 10 $\mathrm{km}$ offshore to less than $300 \mathrm{~m}$ nearshore (Fig. 3). This spatial resolution is consistent with the unstructured computational mesh set up by Gallagher et al. for high-resolution hindcast of nearshore wave climate in Ireland with Wavewatch III (WW III) [7]. The model runs with 31 exponentially spaced frequencies ranging from 0.05 to $1 \mathrm{~Hz}, 30$ evenly spaced directions and a time step of $15 \mathrm{~min}$. In the nearshore areas, the wave energy dissipation by bottom friction is parametrised according to the bottom types and the associated heterogeneous roughness length scale. This heterogeneous parameterisation is found to improve numerical estimates during storm events $[32,33]$. The nearshore bottom roughness parameter is determined according to Guillou et al. [34] on the basis of maps established by sedimentologists and observations for different bottom types compiled by Soulsby [35]. The offshore bottom roughness is set to an uniform value of $k_{n}=10.5 \mathrm{~mm}$. Wind velocity components at $10 \mathrm{~m}$ above the free surface are provided at a time step of three hours and a spatial resolution of $10 \mathrm{~km}$ by the meteorological model ALADIN (Aire Limitée, Adaptation dynamique, Développement InterNational, Météo-France) [36]. Following previous studies dedicated to the 
effects of tide on wave energy resource assessments [37, 38], SWAN integrates the variations of the tidal free-surface elevation and the depth-averaged currents predicted by the bidimensional horizontal circulation model TELEMAC 2D [39] set up at an extended computational grid covering the initial SWAN unstructured mesh. The wave model is finally driven by the wave components (significant wave height, peak period, direction and spreading) predicted by a regional run of Wavewatch III at the scale of the north-eastern Atlantic ocean with a spatial resolution of $18 \mathrm{~km}$ and a time step of three hours in the context of the IOWAGA (Integrated Ocean WAves for Geophysical and other Applications) project. WWIII parameters are first interpolated at nine locations evenly spaced at the open boundaries of SWAN computational domain. Input waves components are then provided at every boundary points and time steps of SWAN following the interpolation procedure described in its technical documentation [31].

The wave model is run during eight years between 2004 and 2011 which corresponds to a period when most measurements and forcings were available. It took approximately $576 \mathrm{CPU}$ hours to perform all the model simulations, using 8 cores of a 2048 core system, based on Intel Xeon processors.

Model performances are assessed with the standard statistical parameters of the mean absolute error

$$
\mathrm{MAE}=\frac{1}{N} \sum_{i=1}^{i=N}\left|x_{i}-y_{i}\right|
$$

the index of agreement introduced by Willmott [40] as

$$
\mathrm{RE}=1-\frac{\sum_{i=1}^{i=N}\left(x_{i}-y_{i}\right)^{2}}{\sum_{i=1}^{i=N}\left(\left|x_{i}-\bar{x}\right|+\left|y_{i}-\bar{x}\right|\right)^{2}}
$$




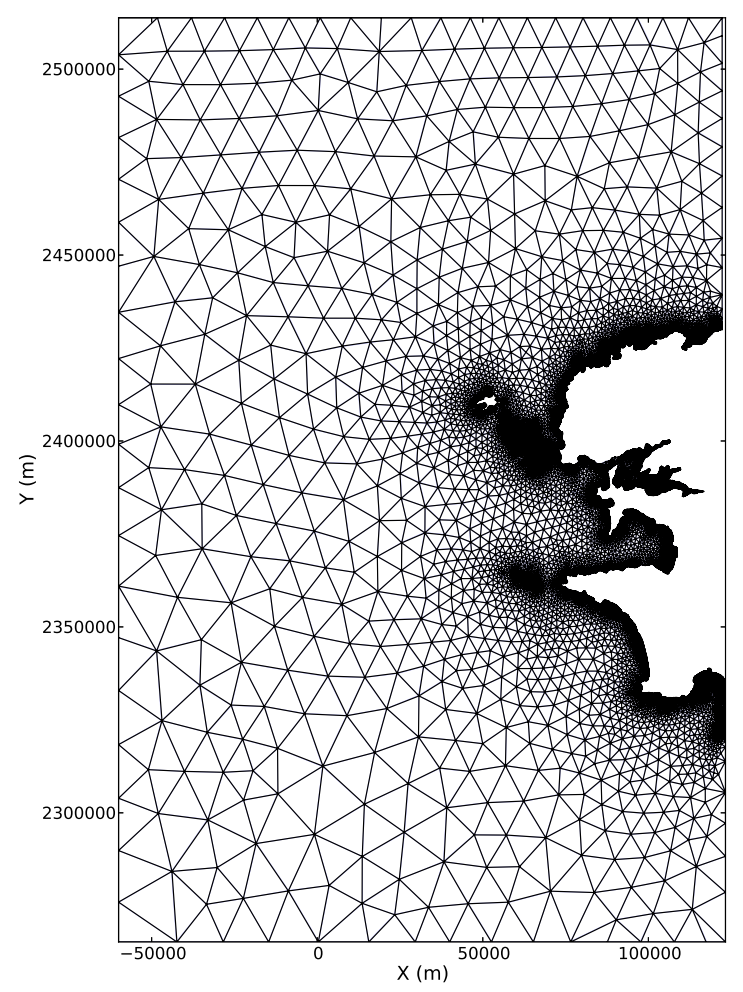

Figure 3: Computational unstructured grid for the SWAN model.

and the Pearson's correlation coefficient

$$
\mathrm{R}=\frac{\sum_{i=1}^{i=N}\left(x_{i}-\bar{x}\right)\left(y_{i}-\bar{y}\right)}{\left(\sum_{i=1}^{i=N}\left(x_{i}-\bar{x}\right)^{2} \sum_{i=1}^{i=N}\left(y_{i}-\bar{y}\right)^{2}\right)^{1 / 2}}
$$

where $N$ is the number of data in the discretised time series considered, $\left(x_{i}\right)$ and $\left(y_{i}\right)$ represent the two sets of measured and simulated values and $\bar{x}$ and $\bar{y}$ are the mean values of observed and modeled data, respectively. 


\section{Evaluation of model predictions}

\subsection{Wave data}

Available data here used are divided between archived wave buoys measurements of the French CANDHIS database ("Centre d'Archivage National de Données de Houle In Situ", Cerema; points 02902, 02911 and 02914) and observations acquired during measurements campaigns conducted off and in the bay of Douarnenez (points E1 to E3 and T1 to T3) (Fig. 1-b). The resulting database includes thus long term observations covering globally the period of interest (wave buoys 02902 and 02911) and medium (wave buoy 02914) to short-term measurements (wave buoys E1 to E3 and T1 to T3) (Table 1). The instrumentation network was deployed in offshore water depths up to $110 \mathrm{~m}$ off Ushant island (point 02902) and coastal areas by mean water depths of $15 \mathrm{~m}$ off beaches of the bay of Douarnenez (points E3, T2 and T3). Further details about this complementary measurement campaign realised in the bay of Douarnenez are available in Guillou [41].

\subsection{Comparison with point measurements}

The emphasis is here put on the local comparison of wave model predictions with available wave-buoys observations. Nevertheless, the quality of numerical results issued from the depth-averaged circulation model TELEMAC 2D has also been estimated. A preliminary confirmation of model predictions has been performed against water depth's observations in harbors of Le Conquet and Brest of the tide gauge network RONIM ("Réseau d'Observation du NIveau de la Mer"). This evaluation has been extended to mean near-surface spring tidal currents' measurements compiled by the SHOM ( "Service Hydro- 
Table 1: Description of the available wave measurements campaigns. Coordinates are indicated in meters according to the French system Lambert II étendu.

\begin{tabular}{ccccc}
\hline Wave & \multicolumn{2}{c}{ Coordinates } & Water depth & Measurement \\
buoys & $\mathrm{X}(\mathrm{m})$ & $\mathrm{Y}(\mathrm{m})$ & $(\mathrm{m})$ & campaigns \\
\hline 02902 & 3253 & 2419754 & 110 & $01 / 2004 \rightarrow 11 / 2011$ \\
02911 & 59210 & 2390790 & 60 & $10 / 2005 \rightarrow 12 / 2011$ \\
\hline 02914 & 90773 & 2316500 & 105 & $11 / 2009 \rightarrow 02 / 2010$ \\
\hline E1 & 47729 & 2375671 & 97 & $04 / 2005$ \\
E2 & 86399 & 2367927 & 40 & $04 / 2005+09 / 2005$ \\
E3 & 104895 & 2374699 & 16 & $04 / 2005+09 / 2005$ \\
T1 & 28587 & 2370689 & 115 & $04 / 2006 \rightarrow 05 / 2006$ \\
T2 & 105910 & 2369966 & 16 & $04 / 2006 \rightarrow 05 / 2006$ \\
T3 & 105519 & 2374663 & 15 & $04 / 2006 \rightarrow 05 / 2006$ \\
\hline
\end{tabular}

graphique et Océanographique de la Marine") at eight points titled S1 to S8 evenly spaced over the computational domain (Fig. 1-b). Predictions reproduce generally well the temporal variations of the amplitude and direction of the currents at the eight sites considered (Fig. 4). Although the model tends to overestimate the currents amplitude at point S5, differences are globally restricted to $15 \%$. The currents' direction is fairly well approached even in areas influenced by the formation of headland-associated eddies (point S7).

The evaluation of wave model predictions is based on statistics computed for the significant wave height $H_{s}$ and the peak period $T_{p}$ at the nine locations considered over the different periods of measurements (Table 2). Predictions reproduce fairly well the temporal evolutions of long-term observations at 

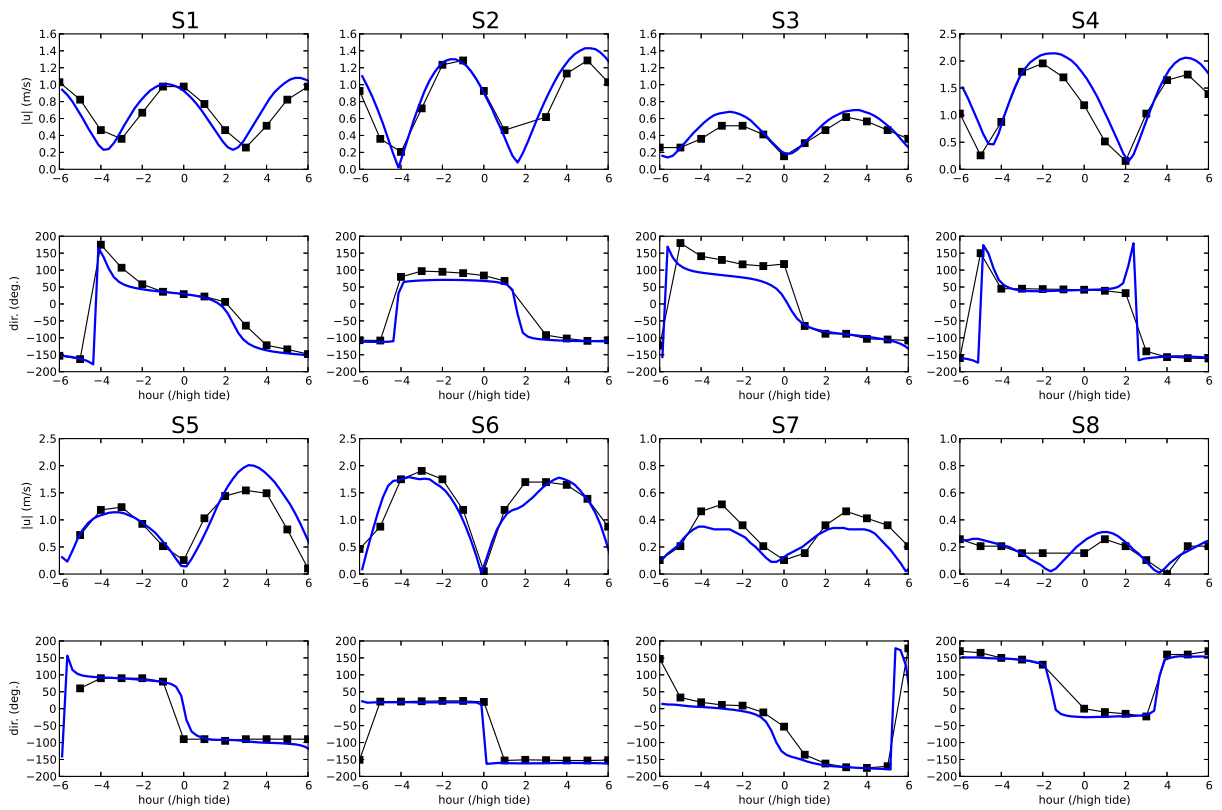

Figure 4: Measured (black line) and computed (blue line) time series of (top) the nearsurface tidal current amplitude and (bottom) its direction (anticlockwise convention from the East) at points $\mathrm{S} 1$ to $\mathrm{S} 8$ for spring tidal conditions. 
offshore locations 02902 and 02911 (Fig. 5). The associated statistics (Table 2) fall in the range of estimations performed by Gonçalves et al. [19] at point 02902 and Boudiere et al. [13] at point 02911. At both measurement sites, good agreement is obtained for $H_{s}$ with indexes RE over 0.93 (Table 2). The quality of model predictions at these offshore locations is also exhibited with computed correlation coefficients over $94 \%$. Whereas increased differences are obtained in peak period estimations, the associated indexes of agreement remain over 0.81 . On medium and short-term measurements, comparisons between numerical results and observations reveal slightly better estimations of $H_{s}$ in deep waters (points 02914 and T1) than in coastal waters (points T2 and T3) (Table 2). This comparison can not be accurately established between points E1, E2 and E3 as measurements cover different periods of time in offshore and nearshore waters. Differences obtained at coastal locations appear primarily in the bay of Douarnenez where the model tends to overestimate $H_{s}$ measurements at point T2 while underestimating it at points E3 and T3 (Fig. 6). Nevertheless, predictions of the significant wave height remain satisfactory with a minimum index of agreement $R$ equal to 0.85 at point T3. The model approaches also the observed semi-diurnal modulation of the significant wave height induced by the tidal current and particularly noticeable at point E2 in September 2005. Although the correlation coefficient $\mathrm{R}$ reaches values under $60 \%$ at points $\mathrm{E} 1$ and $\mathrm{T} 3$ for the estimation of the peak period (Table 2), $T_{p}$ predictions are in general good agreement with measurements reproducing the observed increase during storm events. No particular bias is thus denoted on predictions of $H_{s}$ and $T_{p}$ at the nine available measurements sites. 
Table 2: Overall statistics for the significant wave height $H_{m 0}$ and the peak period $T_{p}$ at the 9 measurements points considered.

\begin{tabular}{ccccccc}
\hline Wave & \multicolumn{3}{c}{$H_{m 0}$} & & \multicolumn{3}{c}{$T_{p}$} \\
buoys & MAE & RE & R & MAE & RE & R \\
& $(\mathrm{m})$ & & & $(\mathrm{s})$ & & \\
\hline 02902 & 0.47 & 0.93 & 0.94 & 1.21 & 0.81 & 0.68 \\
02911 & 0.35 & 0.96 & 0.96 & 1.07 & 0.84 & 0.73 \\
\hline 02914 & 0.39 & 0.98 & 0.96 & 1.29 & 0.83 & 0.71 \\
\hline E1 & 0.32 & 0.93 & 0.89 & 1.21 & 0.75 & 0.59 \\
E2 & 0.16 & 0.96 & 0.95 & 0.89 & 0.87 & 0.78 \\
E3 & 0.09 & 0.94 & 0.94 & 1.08 & 0.80 & 0.64 \\
T1 & 0.22 & 0.95 & 0.92 & 0.96 & 0.86 & 0.74 \\
T2 & 0.08 & 0.91 & 0.89 & 1.17 & 0.76 & 0.59 \\
T3 & 0.09 & 0.85 & 0.88 & 1.53 & 0.69 & 0.50 \\
\hline
\end{tabular}

\section{Characterisation of the wave energy resource}

\subsection{Spatial distribution of energetic patterns}

Fig. 7 displays the predicted average annual wave power in the Sea of Iroise over the period 2004-2011. As pointed out by Rusu and Guedes Soares [16], whereas a close correlation exists between the significant wave height $H_{s}$ and the wave power $P$, the resulting fields may present local differences (Figs. 2 and 7) exhibiting the influence of the group velocity on the computation of the wave energy flux (Eqs. 3 and 4). In the present investigation, slight differences are exhibited in the nearshore areas.

The offshore mean wave power estimated around $P=40 \mathrm{~kW} \mathrm{~m}^{-1}$ under- 

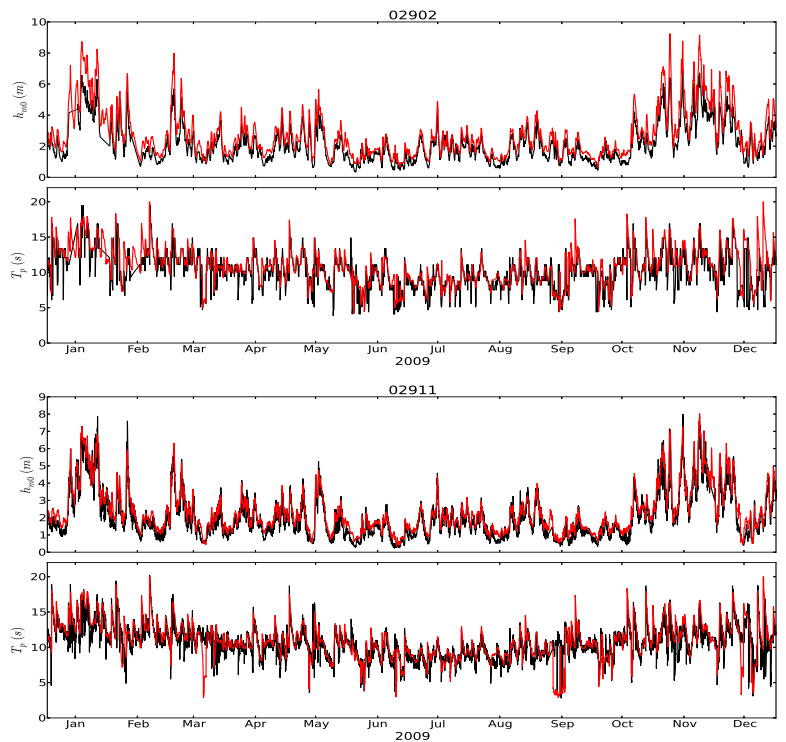

Figure 5: Measured (black line) and computed (red line) time series of the significant wave height and the peak period at wave buoys 02902 and 02911 in 2009.
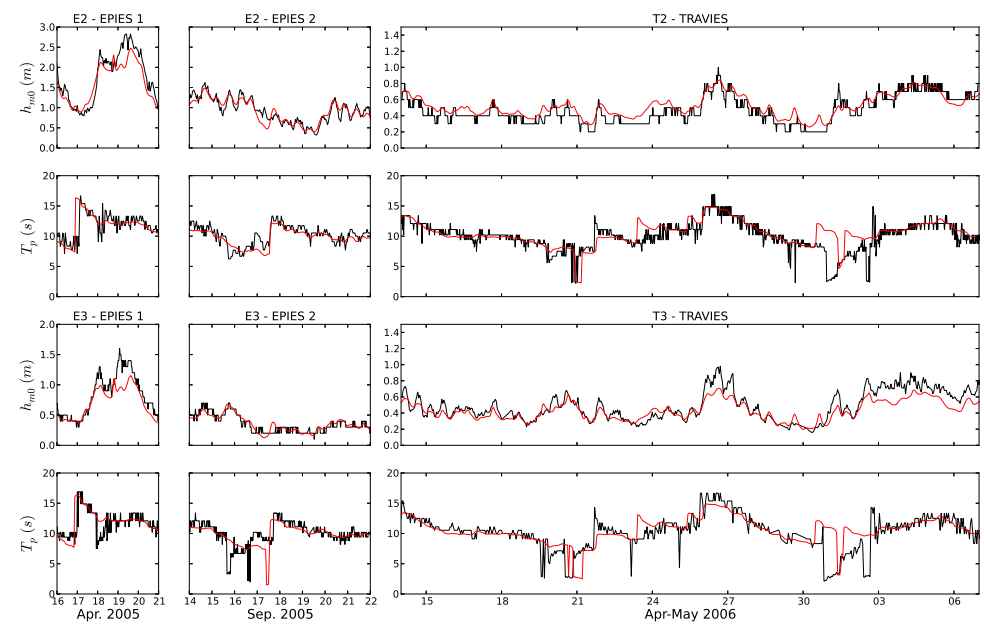

Figure 6: Measured (black line) and computed (red line) time series of the significant wave height and the peak period at wave buoys E2 and E3 in April and September 2005 and T2 and T3 in April-May 2006. 


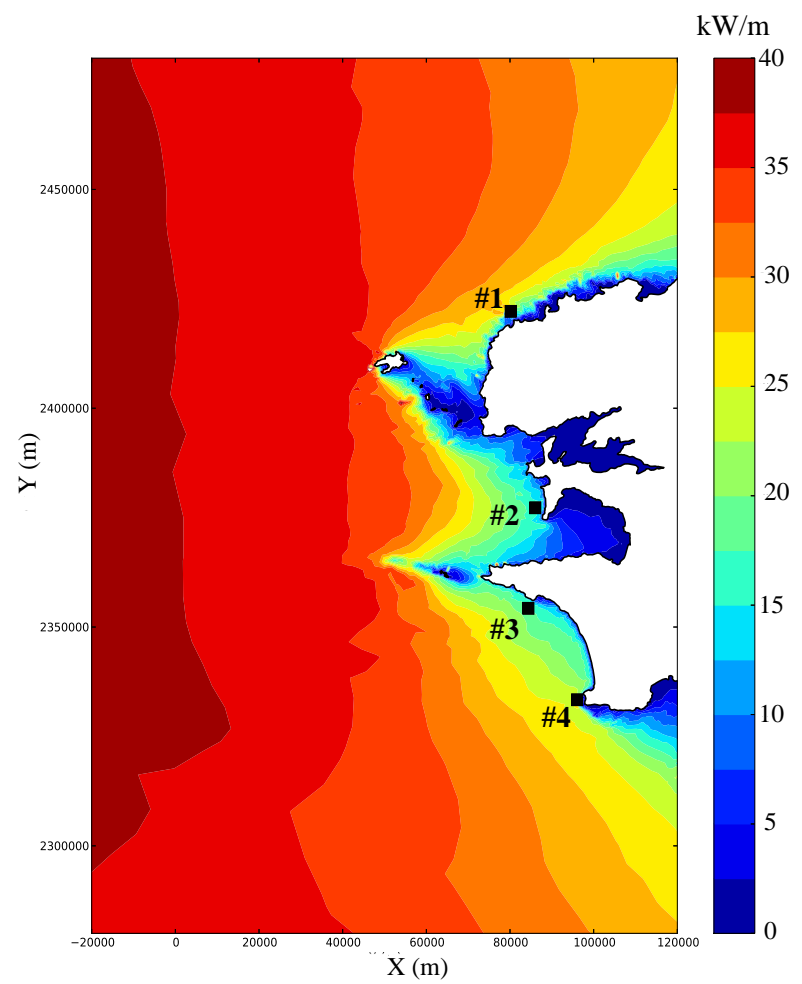

Figure 7: Predicted annual average wave power in the Sea of Iroise with the locations of points \#1 to \#4.

goes a slight decrease of $5-8 \mathrm{~kW} \mathrm{~m}^{-1}$ over the western deepest region. This results in a strong wave power of $P=35 \mathrm{~kW} \mathrm{~m}^{-1}$ off the isle of Ushant. The dissipation of wave energy is more significant in the eastern nearshore areas where waves experience strong energy dissipation by bottom friction and wave breaking. The resulting coastal mean wave power decreases globally to values below $12 \mathrm{~kW} \mathrm{~m}^{-1}$ in water depths under $20 \mathrm{~m}$. The spatial distribution of the average wave energy flux in the nearshore areas is furthermore characterised by a strong variability extending from values around $20 \mathrm{~kW} \mathrm{~m}^{-1}$ in exposed regions of the northern coastline, the Crozon peninsula and the 
bay of Audierne to less than $10 \mathrm{~kW} \mathrm{~m}^{-1}$ in sheltered areas behind the isles of Ushant and Sein as well as in the bays of Brest and Douarnenez.

\subsection{Inter-annual evolution}

As the present assessment provides potential WEC developers with only averaged quantities of the wave power in the Sea of Iroise, further investigation is conducted on the temporal variability of energy resource production. Indeed, as demonstrated by recent statistical studies [42, 43], a relative uncertainty exists in the characterisation of wave power closely related to the variability in the wave climate. This variability has to be characterised in the Sea of Iroise for the implementation of WEC devices. On the basis of a seven-years modelling between 2005 and 2011, Neill and Hashemi [6] have recently exhibited a strong inter-annual variability of wave power at the scale of the northwest European shelf seas. Their assessment of the wave energy resource demonstrates that the annual fluctuations in wave power was predominantly associated with the winter variability of $P$ in close correlation with the evolution of the North Atlantic Oscillation (NAO). This confirms previous investigations conducted by Woolf et al. [5] or Gallagher et al. [7] who demonstrated that the NAO was the leading mode of inter-annual variability in monthly mean wave heights.

The time-series of the wave energy flux averaged over SWAN computational domain (Fig. 8) exhibits this inter-annual variability. Although the wave power remains nearly stable between May and September, significant annual differences are obtained during autumn and winter. This is especially the case between November 2008 and 2009 when the wave energy flux varies from $34 \mathrm{~kW} \mathrm{~m}^{-1}$ to $118 \mathrm{~kW} \mathrm{~m}^{-1}$. The quantification of wave power appears 
thus to be closely related with the period of computation. This close relationship explains the differences obtained between the estimations of the offshore wave power in the Sea of Iroise. In the present investigation, the mean offshore wave energy flux is estimated around $P=40 \mathrm{~kW} \mathrm{~m}^{-1}$. This value remains thus lower than the quantification of $P=50 \mathrm{~kW} \mathrm{~m}^{-1}$ conducted by Mattarolo et al. [11] on the basis of large-scale modelling at the scale of the European continental shelf over a period of 23 full years (19792001). It lies also over the evaluation of $P=28 \mathrm{~kW} \mathrm{~m}^{-1}$ recently performed by Gonçalves et al. [19] in the western French coast for the three-years period between 1998 and 2000. Although these differences can be partly explained by various wave models, spatial and temporal resolutions, the variability of wave climate between the simulation periods appears also to be taken into account.

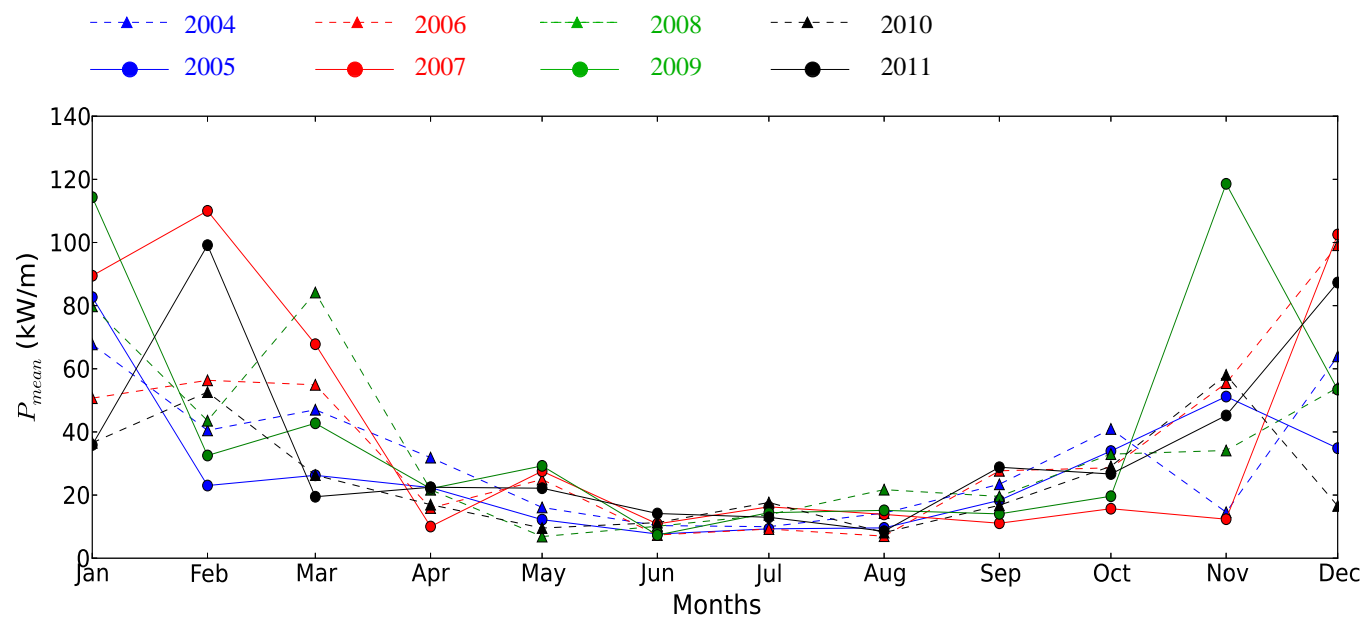

Figure 8: Yearly time series of the overall predicted wave power in the Sea of Iroise. 


\subsection{Seasonal evolution}

Fig. 9 displays the map of the average wave power predicted for each month over the eight-years period considered. The seasonal evolution of the wave energy resource in the Sea of Iroise is in accordance with largescale estimations of Neill and Hashemi [6]. While the resulted distribution depends on the period of computation in relation to significant inter-annual variability, a clear contrast is exhibited between energetic and low-energetic months. As pointed out by Gonçalves et al. [19] in the western French coast, the most energetic conditions appear in winter in relation to rougher wind sea climates. The offshore wave power remains globally over $45 \mathrm{~kW} \mathrm{~m}^{-1}$ between November and March reaching values over $75 \mathrm{~kW} \mathrm{~m}^{-1}$ in December and January. With an exception for the month of October when the offshore mean wave energy flux reaches $35 \mathrm{~kW} \mathrm{~m}^{-1}$, mean deep-waters predictions are globally restricted to values below $20 \mathrm{~kW} \mathrm{~m}^{-1}$ for the rest of the year. The evolution of wave power between energetic and low-energetic months is furthermore more marked at the beginning than at the end of the year. The transition of wave power between the months of March and April is thus more significant than between the months of September and October or October and November.

The seasonal evolution of wave power in the Sea of Iroise presents however a strong variability in close relationship with the inter-annual variability of the North-Atlantic wave climate. It is apparent from Fig. 8 that the monthly predicted wave energy flux does not follow the same trend during each year considered. Whereas January appears on average as the most energetic month, February is found to be more energetic in 2007 and 2011. The 

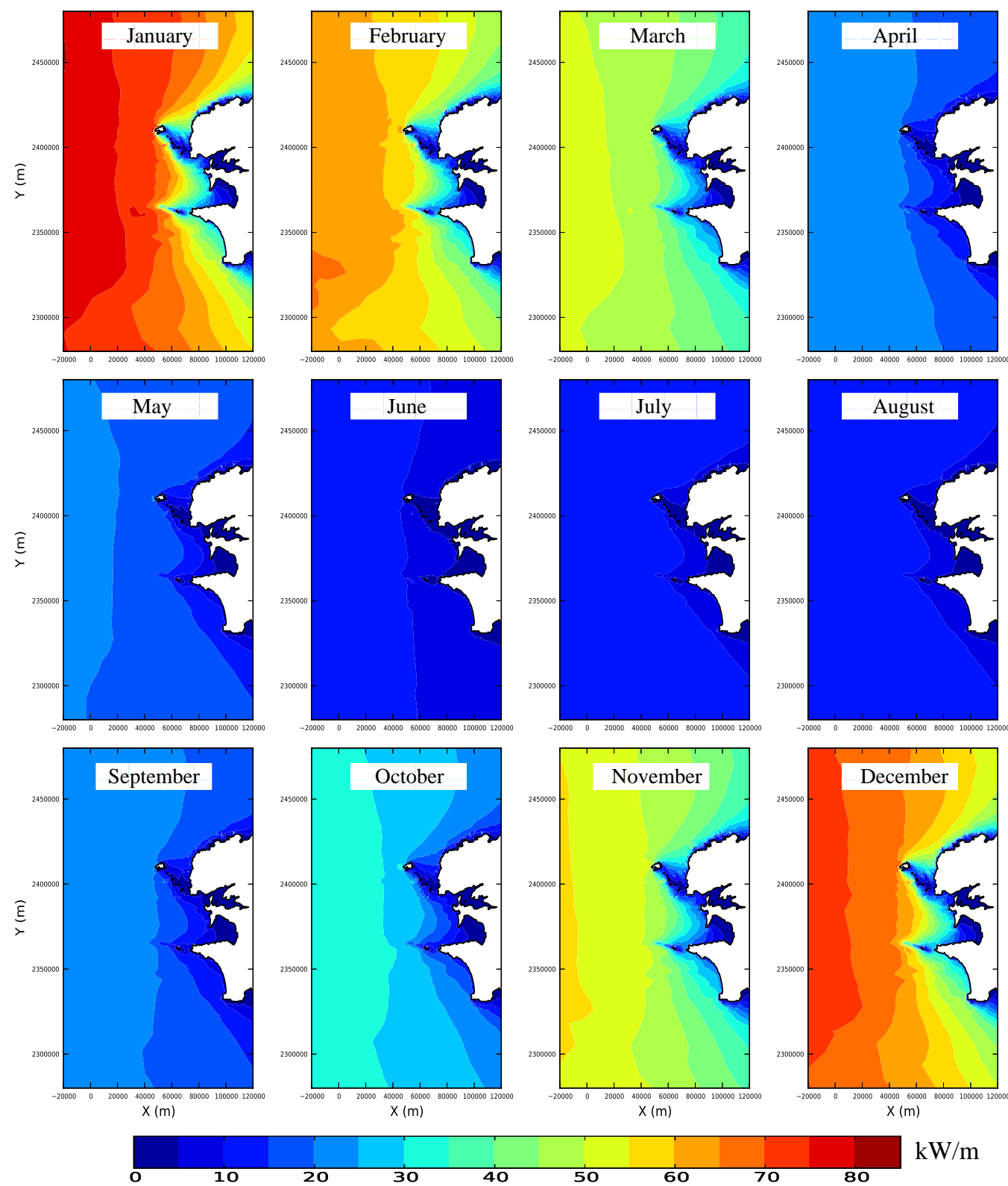

Figure 9: Average monthly evolution of wave power in the Sea of Iroise over the period 2004-2011. 
most energetic period is furthermore obtained in November 2009 with mean wave power reaching $118 \mathrm{~kW} \mathrm{~m}^{-1}$ over the computational domain. Considering the average predictions in Fig. 9, November is however classified at rank four among the most energetic months. The inter-seasonal variability of wave power is clearly exhibited in Fig. 10 which displays the monthly predictions in January, February and March 2008 and 2011. An opposite situation is obtained between these two years with energetic conditions appearing (1) in 2008 during the months of January and March and (2) in 2011 during the month of February.

As pointed out by Neill and Hashemi [6], when considering a typical year, differences may also appear between the most energetic months in the geographic locations of peak wave power. Previsions obtained in 2007 at the scale of the European shelf seas were thus exhibiting peak wave power on the northwest of Scotland and Ireland in January and March while displaying focused wave energy flux on the Celtic Sea and Bay of Biscay in February. At the local scale of the Sea of Iroise, smoothed differences are here obtained for the period of interest between 2004 and 2011. Synoptic investigations of monthly predictions confirm that the nearshore spatial distribution of the wave energy flux remains nearly the same with peak wave power matching the sites identified on the overall average field (Fig. 7).

\section{Local analysis of wave power}

\subsection{General selection}

Several different technologies are currently in development for transforming wave power into electricity [44] with operational range reaching maximum 

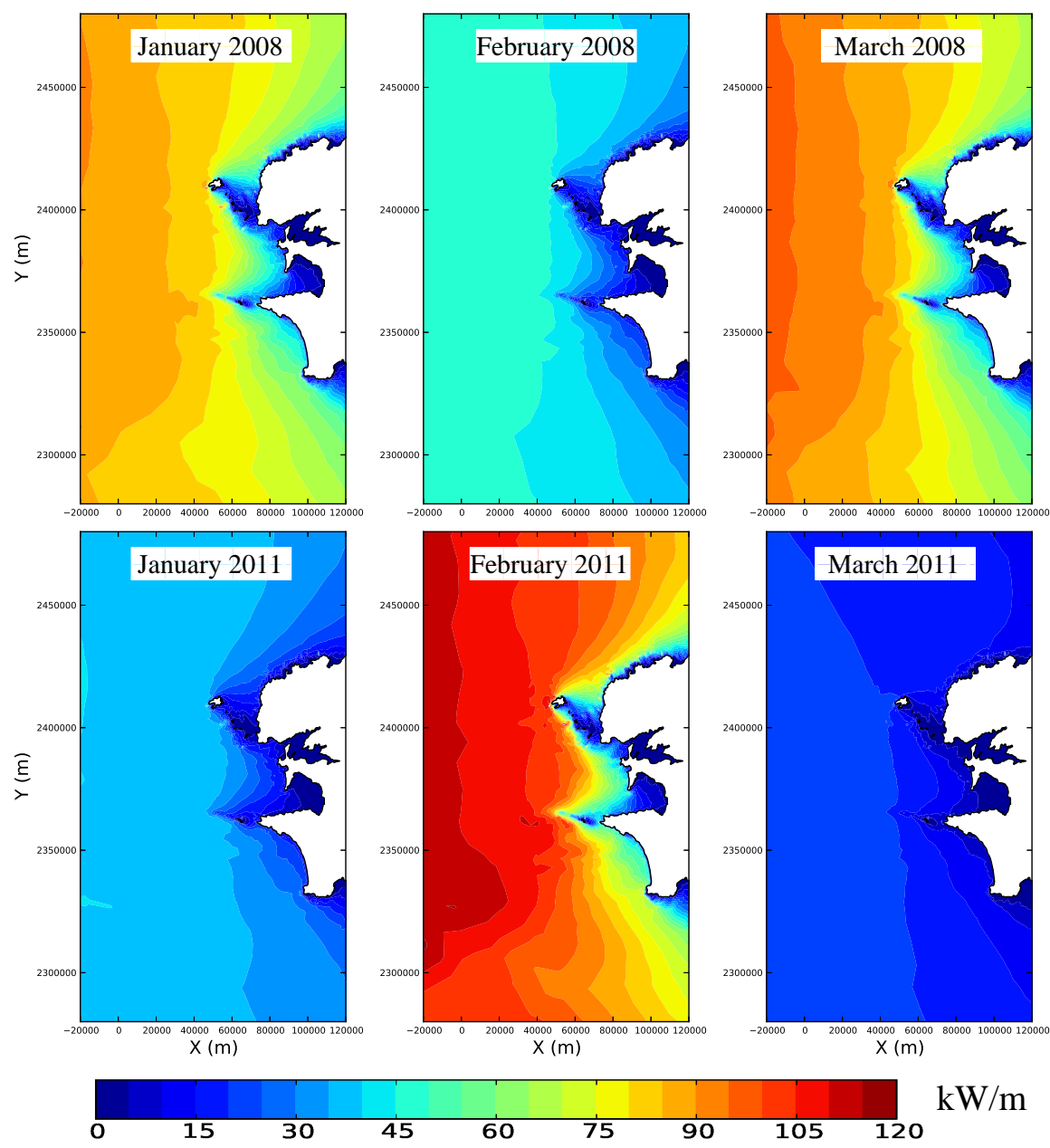

Figure 10: Monthly average wave power in the Sea of Iroise in January, February and March 2008 and 2011.

efficiency in restricted intervals of periods and directions. In the perspective of WEC selection, design and optimisation, the present assessment of the wave energy flux is investigated further at nearshore locations with the largest energy along the coast of western Brittany. Taking into account the population density in the proximity of these areas, sites located off the isles 
of Ushant and Sein are not considered here. Four locations titled \#1 to \#4 are retained in water depths between 15 and $32 \mathrm{~m}$ at a distance to the coastline around $2.1 \mathrm{~km}$ (Fig. 7, Table 3). The associated areas correspond to the major expositions to the North Atlantic incoming waves: along the northern coastline (point \#1), off the Crozon peninsula (point \#2), in the bay of Audierne (point \#3) and off the headland of Penmarc'h (point \#4). While the average nearshore wave power lies below $12 \mathrm{~kW} \mathrm{~m}^{-1}$, these hots spots concentrate the wave energy flux with mean values varying from $15.1 \mathrm{~kW} \mathrm{~m}^{-1}$ off the Crozon Peninsula to $23.3 \mathrm{~kW} \mathrm{~m}^{-1}$ off the headland of Penmarc'h.

Table 3: Location, water depth, distance to the coastline and mean wave energy flux computed in 2004-2011 at sites \#1 to \#4.

\begin{tabular}{cccccc}
\hline Sites & $\begin{array}{c}\mathrm{X} \\
(\mathrm{m})\end{array}$ & $\begin{array}{c}\mathrm{Y} \\
(\mathrm{m})\end{array}$ & $\begin{array}{c}\text { Depth } \\
(\mathrm{m})\end{array}$ & $\begin{array}{c}\text { Distance to the } \\
\text { coastline }(\mathrm{km})\end{array}$ & $\begin{array}{c}P_{\text {mean }} \\
\left(\mathrm{kW} \mathrm{m}^{-1}\right)\end{array}$ \\
\hline$\# 1$ & 80159 & 2422126 & 15.5 & 2.2 & 16.6 \\
$\# 2$ & 86038 & 2377260 & 27.5 & 2.3 & 15.1 \\
$\# 3$ & 84396 & 2354266 & 31.0 & 2.1 & 17.8 \\
$\# 4$ & 96045 & 2333391 & 24.3 & 2.1 & 23.3 \\
\hline
\end{tabular}

\subsection{Distributions against periods and directions}

These four locations present nearly the same distributions of wave power against peak periods (Fig. 11). Waves with longest periods over $12 \mathrm{~s}$ contribute during nearly $35 \%$ of the time to the maximum values of the wave energy flux. The local mean wave power exceeds, in this range of periods, $31 \mathrm{~kW} \mathrm{~m}^{-1}$ reaching $47 \mathrm{~kW} \mathrm{~m}^{-1}$ off Penmarc'h headland. Waves with periods between 8 and $12 \mathrm{~s}$ are the most frequent with a percentage of occurrence 
estimated around $54 \%$. The associated average wave energy flux is however reduced to values between 8 and $13 \mathrm{~kW} \mathrm{~m}^{-1}$ at the four locations considered. In comparison, short-period waves appearing during $12 \%$ of the time have a negligible contribution reduced to mean values below $4.5 \mathrm{~kW} \mathrm{~m}^{-1}$.
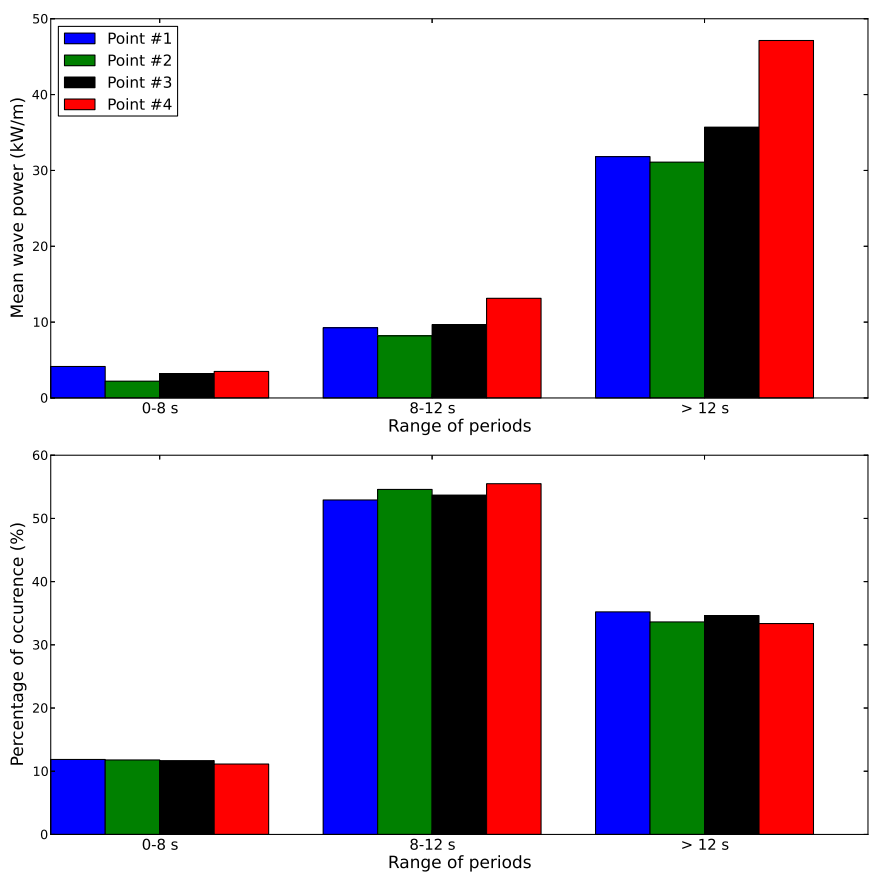

Figure 11: (Top) Average wave power and (Bottom) percentage of occurrence for peak periods between (1) 0 and $8 \mathrm{~s},(2) 8$ and $12 \mathrm{~s}$ and (3) over $12 \mathrm{~s}$ at the four locations \#1 to \#4.

Although North Atlantic waves come predominantly from west and northwest [20], the distribution of wave power against the incoming direction presents more variabilities (Fig. 12) in relation to nearshore processes like depth and/or current-induced refraction and dissipation by bottom friction and wave breaking. The maximum energy density is obtained off Penmarc'h 
headland from the western direction with wave power exceeding $40 \mathrm{~kW} \mathrm{~m}^{-1}$ during more than $16 \%$ of the time. The minimum wave power occurs off Crozon Peninsula in relation to increased dissipation of wave energy by bottom friction. At this site, more than $50 \%$ of wave power lies below $20 \mathrm{~kW} \mathrm{~m}^{-1}$. Points \#1 and \#3 are characterised by intermediate densities of wave energy with incoming waves contributing to values over $20 \mathrm{~kW} \mathrm{~m}^{-1}$ during more than $16 \%$ of the time. At these two locations, the wave energy flux is nearly concentrated along one direction, the north-western direction at point \#1 and the south-western direction at point \#3. WEC selection should thus aim for maximum efficiency in these ranges of periods and directions.

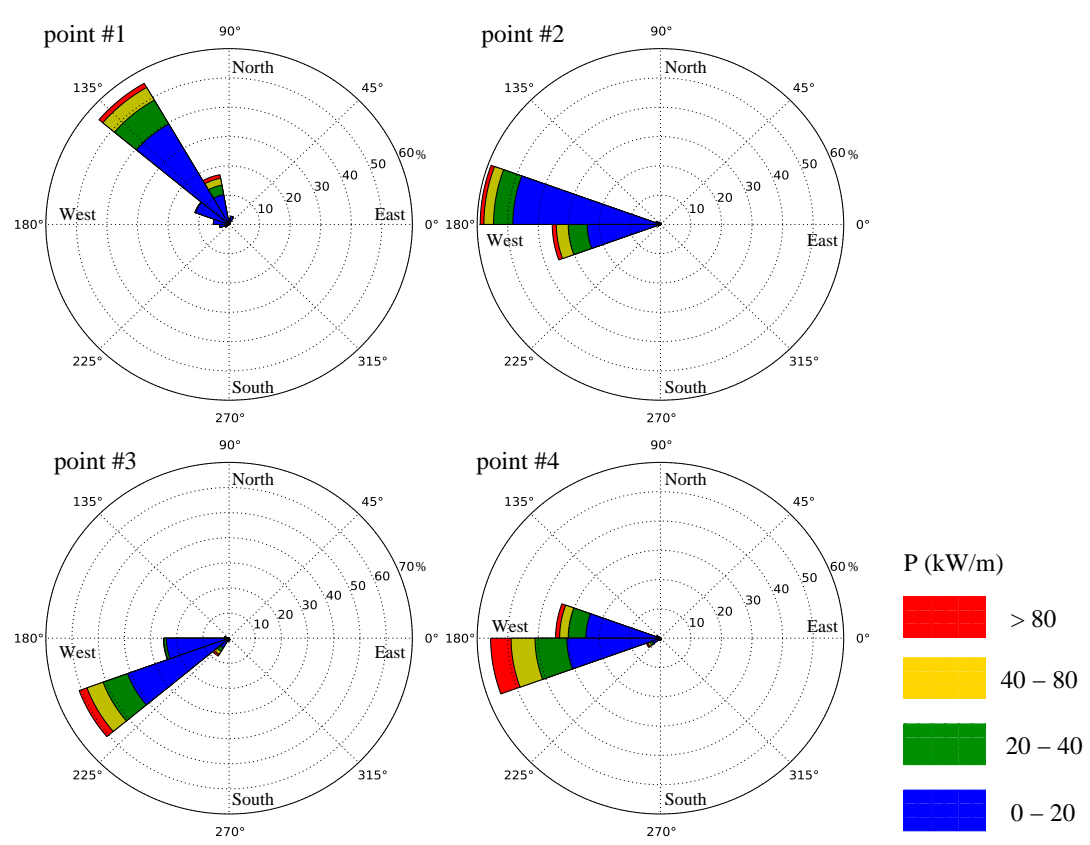

Figure 12: Predicted directional distribution of wave power at points \#1 to \#4 over the period 2004-2011. 


\section{Conclusions}

The wave propagation model SWAN has been set up on an unstructured computational grid to investigate and evaluate the nearshore wave energy resource in the Sea of Iroise. Numerical results have been compared with available in-situ measurements of the significant wave height and the peak period at nine locations between 2004 and 2011. The main outcomes of the present study are the following:

1. Whereas the Sea of Iroise is a high energetic area with mean offshore wave power estimated around $40 \mathrm{~kW} \mathrm{~m}^{-1}$ over the period of interest, a strong energy dissipation is exhibited in shallow water (from $50 \mathrm{~m}$ depth) with mean values decreasing below $15 \mathrm{~kW} \mathrm{~m}^{-1}$ in coastal areas.

2. The variability of the wave energy resource has also been identified. Predictions exhibit strong inter-annual and inter-seasonal variabilities of wave power particularly noticeable over the winter months. At the scale of the Sea of Iroise, the monthly variations of the wave energy flux may thus present opposite situations during the most energetic periods.

3. The energy resource was investigated further at four locations with the largest average wave power exhibiting significant variabilities against the incoming wave directions. While the site located off Penmarc'h headland presents the maximum energy density with wave power exceeding $40 \mathrm{~kW} \mathrm{~m}^{-1}$ during more than $16 \%$ of the time, the locations identified along the northern coastline and off Audierne appear also very interesting for WEC implementation as the wave energy flux is nearly concentrated along one primary direction. 
The implementation of an unstructured version of SWAN gives promising results for the quantification of the wave energy flux in the coastal areas. Whereas the present investigation will benefit from extending comparisons of numerical predictions with nearshore measurements, modelling exhibits the remarkable energy resource in the area of the Sea of Iroise. This refined assessment of wave power provides finally potential developers with relevant results for (1) selecting the implementation and (2) optimising the design of WEC projects.

\section{Acknowledgements}

The authors are particularly grateful to Météo-France for supplying wind fields data obtained with the meteorological model ALADIN over the computational domain. Wave data used at the open boundary of the wave propagation model are issued from regional runs of Wavewatch III in the curse of the IOWAGA project (http://wwz.ifremer.fr/iowaga/Products). Wave buoy data used for model validation was provided by the French CANDHIS database (Cerema). Simulation were performed on computer facilities CAPARMOR (CAlcul PARallèle Mutualisé pour l'Océanographie et la Recherche). The present paper is a contribution to the research programs DIADEMS and FLUSED of the Laboratory of Coastal Engineering and Environment (Cerema, http://www. cerema.fr, http://memphys-lgce.fr.ht).

\section{References}

[1] Shields MA, Woolf DK, Grist EPM, Kerr SA, Jackson AC, Harris RE, Bell MC, Beharie R, Want A, Osalusi E, Gibb SW, Side J. Marine 
renewable energy: The ecological implications of altering the hydrodynamics of the marine environment. Ocean and Coastal Management, 2011, 54:2-9.

[2] Clément A, McCullen P, Falcão A, Fiorentino A, Gardner F, Hammarlund $\mathrm{K}$ et al. Wave energy in Europe: current status and perspectives. Renewable and sustainable energy reviews, 2002, 6:405-431.

[3] Iglesias G, Carballo R. Wave energy potential along the Death Coast (Spain). Energy, 2009, 34:1963-1975.

[4] Liang B, Fan F, Yin Z, Shi H, Lee D. Numerical modelling of the nearshore wave energy resources of Shandong peninsula, China. Renewable Energy, 2013, 57:330-338.

[5] Woolf DK, Cotton PD, Challenor PG. Measurements of the offshore wave climate around the British Isles by satellite altimeter. Philosophical Transactions: Mathematical, Physical and Engineering Sciences, 2003, 361:27-31.

[6] Neill SP, Hashemi MR. Wave power variability over the northwest European shelf seas. Applied Energy, 2013, 106:31-46.

[7] Gallagher S, Tiron R, Dias F. A long-term nearshore wave hindcast for Ireland: Atlantic and Irish Sea coasts (1979-2012). Ocean Dynamics, 2014, 64:1163-1180.

[8] Holthuijsen H. Waves in oceanic and coastal waters. Cambridge University Press, 2007, p. 387. 
[9] Angelis-Dimakis A, Biberacher M, Dominguez J, Fiorese G, Gadocha S, Gnansounou E, Guariso G, Kartalidis A, Panichelli L, Pinedo I, Robba M. Methods and tools to evaluate the availability of renewable energy sources. Renewable and Sustainable Energy Reviews, 2011, 15:11821200.

[10] Gunn K, Stock-Williams C. Quantifying the global wave power resource. Renewable Energy, 2012, 44:296-304.

[11] Mattarolo G, Lafon F, Benoit M. Wave energy resource of the French coasts: the ANEMOC database applied to the energy yield evaluation of wave energy converters. In: Proceedings of the 8th european wave and tidal energy conference, Uppsala, Sweden, 2009.

[12] Pontes MT. Assessing the European wave energy resource. Journal of Offshore Mechanics and Arctic Engineering, 1998, 120:226-231.

[13] Boudiere E, Maisondieu C, Ardhuin F, Accensi M, Pineau-Guillou L, Lepesqueur J. A suitable metocean hindcast database for the design of marine energy converters. International Journal of Marine Energy, 2013, 3-4:40-52.

[14] Bento AR, Martinho P, Campos R, Guedes Soares C. Modeling wave energy resources in the Irish west coast. In: Proceedings of the 30th International conference on ocean, offshore and Arctic engineering (OMAE 2011), number OMAE2011-50346, 2011.

[15] Bento AR, Martinho P, Guedes Soares C. Modeling wave energy 
resources for UK's southwest coast. In: Proceedings of the IEEE OCEANS2011, 2011.

[16] Rusu E, Guedes Soares C. Numerical modelling to estimate the spatial distribution of the wave energy in the Portuguese nearshore. Renewable Energy, 2009, 34:1501-1516.

[17] Iglesias, G, López M, Carballo R, Castro A, Fraguela JA, Frigaard P. Wave energy potential in Galicia (NW Spain). Renewable Energy, 2009, $34: 2323-2333$.

[18] Mouslim H, Babarit A, Clément A, Borgarino B. Development of the french wave energy test site SEM-REV. In: Proceedings of the 8th european wave and tidal energy conference, Uppsala, Sweden, 2009.

[19] Gonçalves M, Martinho P, Guedes Soares C. Wave energy conditions in the western French coast. Renewable Energy, 2014, 62:155-163.

[20] Guedes Soares C, Bento AR, Goncalves M, Silva D, Martinho P. Numerical evaluation of the wave energy resource along the Atlantic European coast. Computers and Geosciences, 2014, 71:37-49.

[21] Zijlema M. Computation of wind-wave spectra in coastal waters with SWAN on unstructured grids. Coastal Engineering, 2010, 57:267-277.

[22] Booij N, Ris RC, Holthuijsen LH. A third-generation wave model for coastal regions, 1. model description and validation. Journal of Geophysical Research, 1999, 104(C4):7649-7666. 
[23] van der Westhuysen AJ. Spectral modeling of wave dissipation on negative current gradients. Coastal Engineering, 2012, 68:17-30.

[24] Hasselmann S, Hasselmann K, Allender JH, Barnett TP. Computations and parameterizations of the nonlinear energy transfer in a gravity wave spectrum. part ii: Parameterizations of the nonlinear transfer for application in wave models. Journal of Physical Oceanography, 1985, 15(11):1378-1391.

[25] Eldeberky, Y. Nonlinear transformation of wave spectra in the nearshore zone. PhD thesis, Delft University of Technology, Department of Civil Engineering, The Netherlands, 1996.

[26] van der Westhuysen AJ. Advances in the spectral modelling of wind waves in the nearshore. PhD thesis, Fac. of Civil Eng., Delft University of Technology, 2007.

[27] Yan L. An improved wind input source term for third generation ocean wave modelling. Technical Report 87-8, Royal Dutch Meteor. Inst. (KNMI), 1987.

[28] Madsen OS, Poon YK, Graber HC. Spectral wave attenuation by bottom friction: theory. In: Proceedings of the 21st International Conference on Coastal Engineering, ASCE, 1988, 492-504.

[29] Battjes J, Janssen J. Energy loss and set-up due to breaking of random waves. In: Proceedings of the 16th International Conference on Coastal Engineering, Hambourg, 1978, 569-587. 
[30] Fairley I, Ahmadian R, Falconer RA, Willis MR, Masters I. The effects of a Severn barrage on wave conditions in the Bristol Channel. Renewable Energy, 2014, 68:428-442.

[31] SWAN team. Swan cycle iii. version $40.91 \mathrm{abc}$ - scientific and technical documentation. Technical report, Delft University of Technology, 2013.

[32] Guillou N. Wave energy dissipation by bottom friction in the English Channel. Ocean Engineering, 2014, 82:42-51.

[33] Roland A, Ardhuin F. On the developments of spectral wave models: numerics and parameterizations for the coastal ocean. Ocean Dynamics, Topical Collection of the 7th International Conference on Coastal Dynamics, 2014, 64, 6: 833-846.

[34] Guillou N, Chapalain G, Duvieilbourg E. Modelling impact of bottom roughness on sea surface temperature in the Sea of Iroise. Continental Shelf Research, 2013, 54:80-92.

[35] Soulsby R. The bottom boundary layer of shelf seas. In: B. (Ed.) Johns, editor, Physical Oceanography of Coastal and Shelf Seas, Elsevier, Amsterdam, 1983, 189-266.

[36] Bénard P Aladin-nh/arome dynamical core; status and possible extension to ifs. In Proceedings of the ECMWF Seminar, 2004, 714-726.

[37] Barbariol F, Benetazzo A, Carniel S, Sclavo M. Improving the assessment of wave energy resources by means of coupled wave-ocean numerical modeling. Renewable Energy, 2013, 60:462-471. 
[38] Hashemi MR, Neill, SP. The role of tides in shelf-scale simulations of the wave energy resource. Renewable Energy, 2014, 69:300-310.

[39] Hervouet JM. Hydrodynamics of free surface flows, modelling with the finite element method. Cambridge University Press, Cambridge, 2007.

[40] Willmott CJ. On the validation of models. Phys. Geogr., 1981, 2(2):219232 .

[41] Guillou N. Rôles de l'hétérogénéité des sédiments de fond et des interactions houle-courant sur l'hydrodynamique et la dynamique sédimentaire en zone subtidale - applications en Manche orientale et à la pointe de la Bretagne. PhD thesis, Université de Bretagne Occidentale, 2007, p. 469

[42] Mackay EBL, Bahaj AS, Challenor PG. Uncertainty in wave energy resource assessment. part 1: historic data. Renewable Energy, 2010, 35(8):1792-1808.

[43] Mackay EBL, Bahaj AS, Challenor PG. Uncertainty in wave energy resource assessment. part 2: variability and predictability. Renewable Energy, 2010, 35(8):1808-1819, 2010.

[44] Falcão AFO Wave energy utilization: a review of the technologies. Renewable \& Sustainable Energy Reviews, 2010, 14:899-918. 